\title{
Optimizing the integrated pulsed amperometric multicycle step waveform for the determination of tetracyclines
}

\author{
Yu-e Cai ${ }^{\text {a,b }}$, Yaqi Cai ${ }^{a}, *$, Yali Shi ${ }^{a}$, Shifen Mou ${ }^{a}$, Yiqiang Lu ${ }^{b}$ \\ a State Key Laboratory of Environmental Chemistry and Ecotoxicology, Research Center for Eco-Environmental Sciences, \\ Chinese Academy of Sciences, Beijing 100085, China \\ ${ }^{\mathrm{b}}$ Department of Chemistry, University of Science and Technology Beijing, Beijing 100083, China
}

Available online 15 December 2005

\begin{abstract}
A method of modified integrated pulsed amperometric detection with multicycle step waveform (Multi-IPAD) following high-performance liquid chromatography (HPLC) was applied for the determination of tetracyclines (TCs) including dimethyltetracycline (DMTC), oxytetracycline (OTC) and tetracycline (TC). The key advantages of the Multi-IPAD are the abilities to enhance sensitivity and reproducibility and the ability to keep working electrode clean through the use of a high-frequent waveform alteration in integration step and the use of a cleaning potential, which is quite different from conventional three-step potential waveform. The analyses were carried out using the mobile phase of acetonitrile-water mixture solution $(10: 90, \mathrm{v} / \mathrm{v})$ containing $1 \%$ perchloric acid on a $\mathrm{C}_{18}$ column at a flow rate of $0.21 \mathrm{~mL} / \mathrm{min}$. The IPAD waveform parameters were optimized to maximize the signal-to-noise ratio $(\mathrm{S} / \mathrm{N})$ and successfully applied for the sensitive detection of TCs. The detection limits $(\mathrm{S} / \mathrm{N}=3$, $20 \mu \mathrm{L}$ injected) were $0.07 \mathrm{mg} / \mathrm{L}$ for DMTC, $0.08 \mathrm{mg} / \mathrm{L}$ for OTC and $0.05 \mathrm{mg} / \mathrm{L}$ for TC. The peak height relative standard deviations (RSDs) of every compound for replicate injection $(n=15)$ determined were below $4.6 \%$.
\end{abstract}

(C) 2005 Elsevier B.V. All rights reserved.

Keywords: Integrated pulsed amperometric detection; Multi-IPAD; Tetracyclines; High-performance liquid chromatography

\section{Introduction}

Tetracyclines (TCs) are broad-spectrum antibiotics against both Gram-positive and Gram-negative bacteria. These compounds are widely used for many infections such as respiratory tract infections, urethritis and multidrug resistant malaria in confined animal feeding operations [1]. At the same time, because of their adverse effects on public health, concerns are raised over the residues of antibiotics in biological products and environment samples.

Many methods have been reported for the detection of antibiotics in various samples. Microbiological assay [2] once used is of less sensitivity and specificity. Thin layer chromatography [3], capillary electrophoresis $[4,5]$ and high-performance liquid chromatography (HPLC) methods were used to determine antibiotics too. Of all these methods, HPLC coupled with different detection techniques such as UV or DAD [6-9], chemilumi-

\footnotetext{
* Corresponding author. Tel.: +86 1062849182.

E-mail address: caiyaqi@ rcees.ac.cn (Y. Cai).
}

nescence [10-12], MS [13-15] and electrochemistry [1,16-22] is the most common method to be used for the analysis of TCs.

Electrochemical methods have attracted much interest owing to its simplicity, non-derivatization, low cost and high degree of sensitivity and selectivity. Direct current amperometry is the simplest method used for catechols, phenols, etc. [23], but the working electrode needs to be cleaned periodically by mechanical polishing or by potential pulse. As an improvement, pulsed amperometric detection (PAD) is composed of a cleaning potential step to remove the fouling of noble metal electrode from the oxidized analytes. Of these PAD methods, triple-potential waveform, quadruple-potential waveform and six-potential waveform were described in many papers [17,24]. Recently, Thiraporn et al. [17] used a triple-potential waveform on an anodized boron-doped diamond thin film (BDD) electrode to analyze TC. Palaharn et al. [1] also reported a flow injection analysis with triple-potential waveform PAD for the determination of TC. IPAD is different from PAD on the point of the signal current is integrating through a rapid cyclic scan during the detection potential step within a pulsed potential 

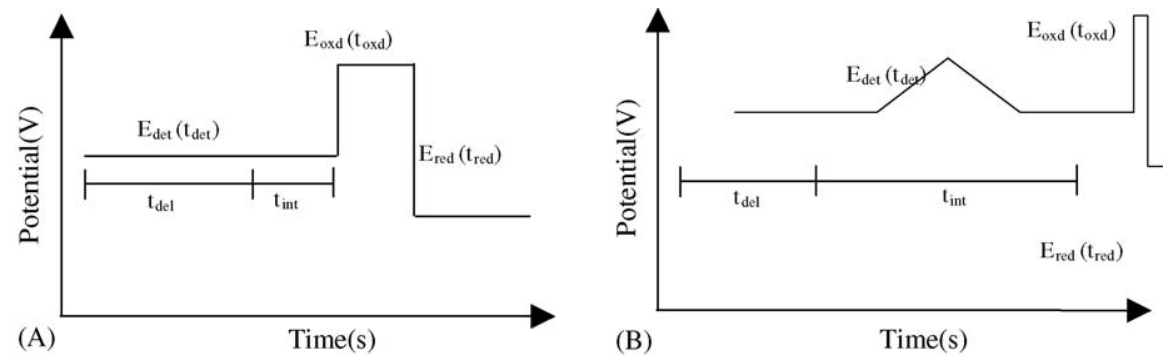

Fig. 1. Potential-time parameters of pulsed amperometric detection waveform. (A) Triple-step PAD waveform and (B) Typical IPAD waveform.
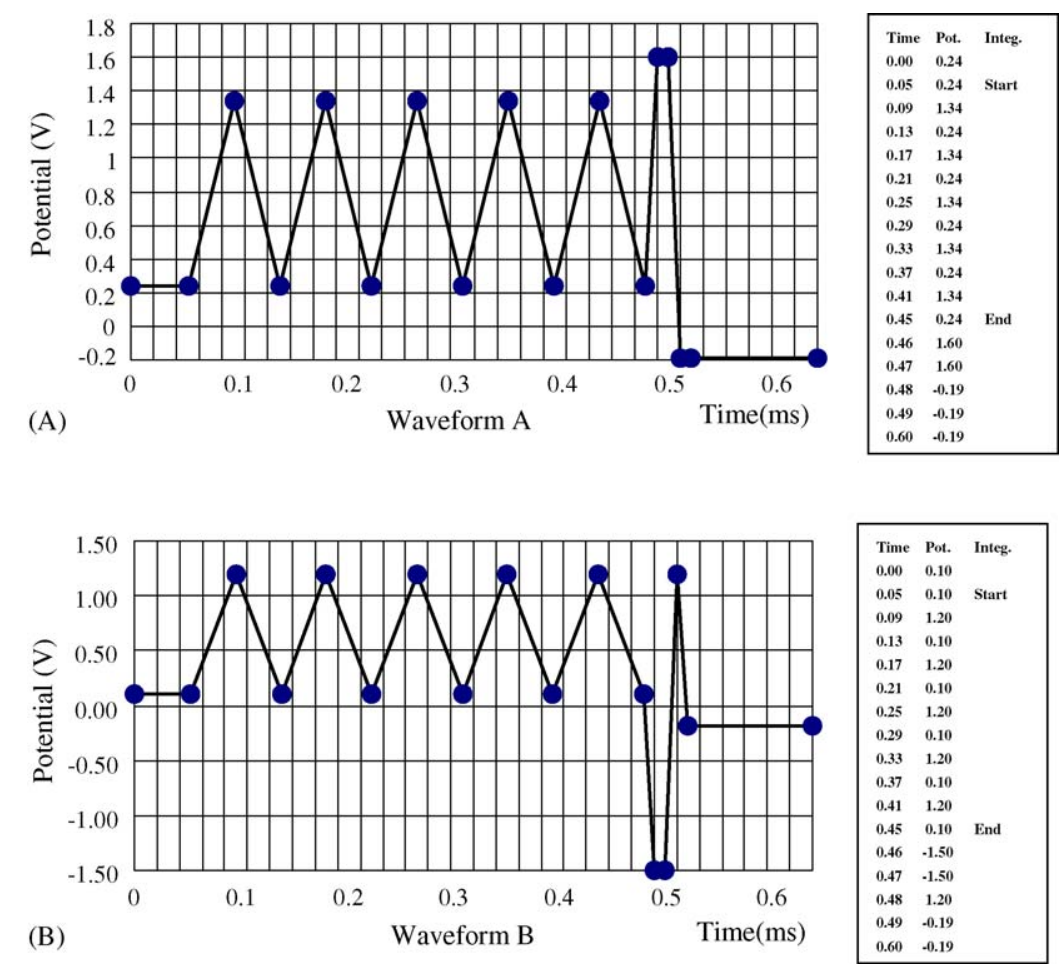

Fig. 2. Potential waveforms investigated in this paper. (A) Multicycle IPAD waveform A and (B) Multicycle IPAD waveform B.

time waveform. The typical waveforms of PAD and IPAD are shown in Fig. 1A and B. IPAD can easily diminish baseline offset and drift occurring in PAD caused by small variations in the mobile phase and changes in the total surface area of the noble-metal electrode as well as analyte-induced effects [25].

Multicycle waveform detection method generally shows lower LOD and higher S/N compared with other waveform formation [25], but it is still not used to analyze the TCs. In addition, nearly all HPLC methods based on electrochemical detection using gold electrode were conducted in basic mobile phase, and the acidic mobile phase was seldom used in such cases. In the present paper, a modified Multi-IPAD waveform at a gold working electrode was investigated for the determination of three TCs in the acidic mobile phase for the first time, which was composed of a multicycle detection step and a positive cleaning and activating potential step (see Fig. 2A). A similar multicycle with a negative cleaning step was also used (see Fig. 2B). To obtain high sensitivity, every step of multicycle waveform was opti- mized. An application to determine oxytetracycline in tablets for animals was carried out.

\section{Experimental}

\subsection{Chemicals and standard solutions}

Purified water produced by a compact ultrapure water system (Barnstead, IA, USA) was used throughout the experiments. Acetonitrile (HPLC) was purchased from Sigma-Aldrich. Perchloric acid was from Tianjin Chemicals, Tianjin, China. Dimethyltetracycline (DMTC), oxytetracycline (OTC) and tetracycline (TC) were purchased from National Institute for the Control of Pharmaceutical and Biological Products, Beijing, China. Stock solutions of each compound were prepared in methanol at a concentration of $100 \mathrm{mg} / \mathrm{L}$ and stored in a refrigerator $\left(4^{\circ} \mathrm{C}\right)$. Working standard solutions were prepared daily with water. OTC tablets for animals was purchased from a animal hospital nearby our laboratory. 


\subsection{Chromatographic instrumentation}

Analyses were carried out with a ICS-2500 chromatographic system (Dionex, Sunnyvale, CA, USA) containing an AS50 antosampler, a GP50 gradient pump and a ED50A electrochemical detector equipped with a thin-layer type PED amperometric cell. The flow-through detection cell consists of a gold working electrode, an $\mathrm{Ag} / \mathrm{AgCl}$ reference electrode and a counter electrode, i.e. the titanium cell body. The seperation was performed using Acclaim Polar Advantage $2 \mathrm{C}_{18}$ silica reversed-phase column $(150 \mathrm{~mm} \times 2.1 \mathrm{~mm}$ I.D., $3 \mu \mathrm{m}, 120 \AA$, Dionex, Sunnyvale, CA, USA) at a mobile phase flow rate of $0.21 \mathrm{~mL} / \mathrm{min}$, the column was installed in the LC30 chromatography oven at a controlled temperature of $30{ }^{\circ} \mathrm{C}$. The mobile phase was a mixture solution of acetonitrile-water $(10: 90, \mathrm{v} / \mathrm{v})(\mathrm{pH} 2)$ containing $1 \%$ perchloric acid. The sample injection volume was $20 \mu \mathrm{L}$. A personal computer equipped with PeakNet 6.3 software was used to acquire and process chromatographic data.

\section{Results and discussion}

\subsection{Seperation conditions in HPLC}

Tetracyclines were successfully separated in an aqueousorganic eluent with $1 \%$ perchloric acid and $10 \%$ (v/v) acetronitrile ( $\mathrm{pH}$ 2) using a $\mathrm{C}_{18}$ column. To avoid the peak tailing, as many other researchers did, we also added $1 \%$ perchloric acid in the mobile phase. Fig. 3 gave the HPLC-Milti-IPAD chromatograms of a standard mixture containing $4 \mathrm{ppm}$ concentration of DMTC and 6 ppm concentrations of OTC and TC. It is important to note that a high concentration of $\mathrm{CH}_{3} \mathrm{CN}$ results in drift background and response decrease to a degree, while low $\mathrm{CH}_{3} \mathrm{CN}$ concentration results in poor peak shape and long retention time. Thus, $10 \% \mathrm{CH}_{3} \mathrm{CN}$ aqueous solution containing $1 \%$ perchloric acid was selected as mobile phase and a in isocratic eluent program was used to perform the separation.

\subsection{Multi-IPAD waveform optimization}

The Multi-IPAD waveform A and waveform B were MultiIPAD waveforms with a positive activating potential (waveform A) and a negative cleaning potential (waveform B), which were investigated separately.
The initial potential value and the oxidation potential value in detection step significantly affected the sensitivity of analysis, especially the oxidation potential; therefore, they were essential to be optimized. A range of $0.85-1.50 \mathrm{~V}$ was chosen to be evaluated based on much work on different metal surface and in different working solution [1,17,23,26,27]. Varied initial potential range of $0-0.3 \mathrm{~V}$ which presented a secondary influence on the $\mathrm{S} / \mathrm{N}$ ratio was also evaluated. When a parameter was optimized, the other values were kept constant. The optimum conditions were obtained by the injections of a standard solution. We investigated the effects on the signal responses and the effects on the noise separately and calculated the $\mathrm{S} / \mathrm{N}$ ratio as the evaluation criterion. Fig. 4 shows the effects of the two detection potentials on $\mathrm{S} / \mathrm{N}$ in waveform $\mathrm{A}$ and waveform B. From studying the curves in Fig. 4, the optimal potential values were chosen: 0.24 and $1.34 \mathrm{~V}$ in waveform $\mathrm{A}$ and 0.10 and $1.20 \mathrm{~V}$ in waveform B.

To get the best analytical performances, the effects of repetition times of the triangular waveform was examined, it was found that when the triangular waveform repeated for five times, the chromatographic system exhibited the highest value of signalto-noise ratio, further increasing the repetition times of the triangular waveform did not nearly have any further positive effects on the value of signal-to-noise ratio. This result was in accordance with ref. [25,27]. In ref. [25,27], it was reported that the maximum benefit of multicycle waveforms was often achieved with four or five cycles.

The brief, relatively high, positive cleaning potential in waveform A was applied to clean the reaction products and impurities adsorbed on the surface of electrode; by using this strong oxidation potential, with such an active potential, some golden oxide is formed on the surface of electrode. Its another function is in activating the gold working electrode in combination with an immediately followed negative potential. In our experiments, it was found that when $1.60 \mathrm{~V}$ and a followed potential of $-0.19 \mathrm{~V}$ were accepted, the chromatographic system provided a satisfactory stability and sensitivity.

In recent years, it has been shown that besides applying brief relatively high positive potential and applying a brief, relatively high, negative potential also had the function of cleaning the reaction products and impurities adsorbed on the surface of electrode [28]. The mechanism about this is not very clear now, but there are two possible explanations. One explanation is proposed

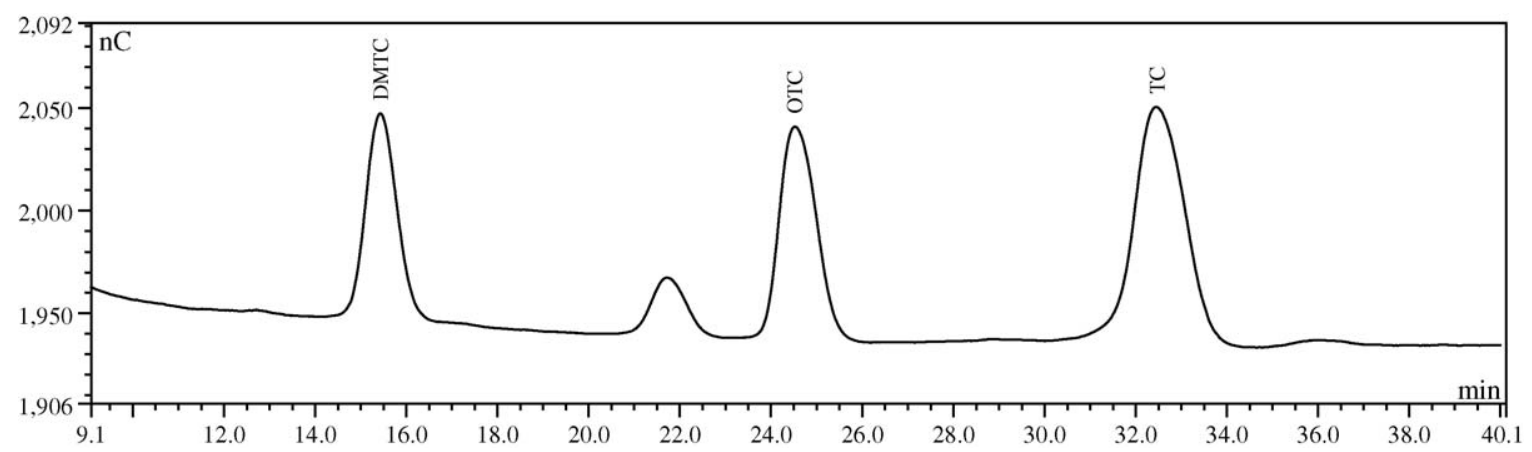

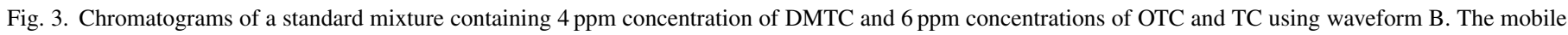
phase was $10 \%(\mathrm{v} / \mathrm{v})$ acetonitrile in water at a flow rate of $0.21 \mathrm{~mL} / \mathrm{min}$. The injection volume was $20 \mu \mathrm{L}$. 


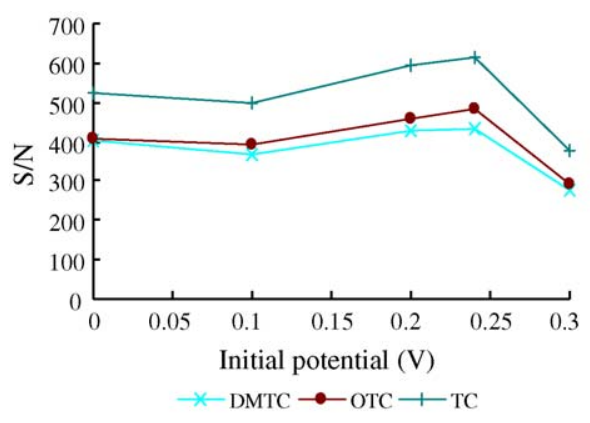

(A) The effect of initial potential on $\mathrm{S} / \mathrm{N}$ in waveform $\mathrm{A}$

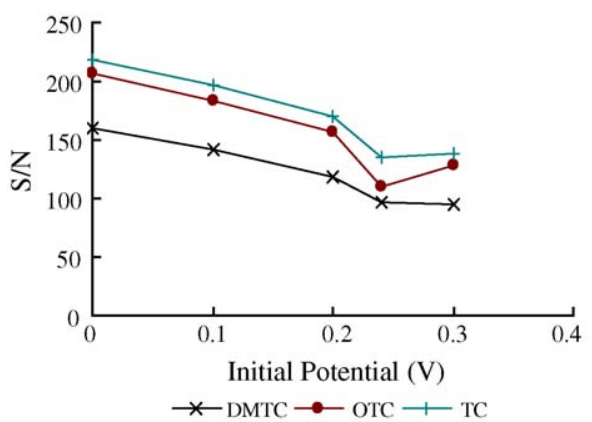

(C) The effect of initial potential on $\mathrm{S} / \mathrm{N}$ in waveform $\mathrm{B}$

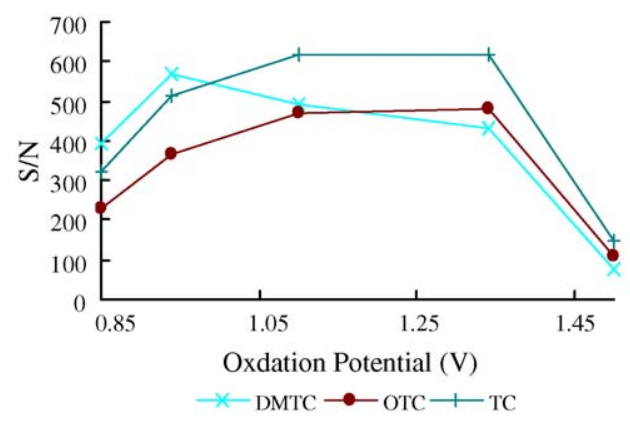

(B) The effect of oxdation potential on $\mathrm{S} / \mathrm{N}$ in waveform $\mathrm{A}$

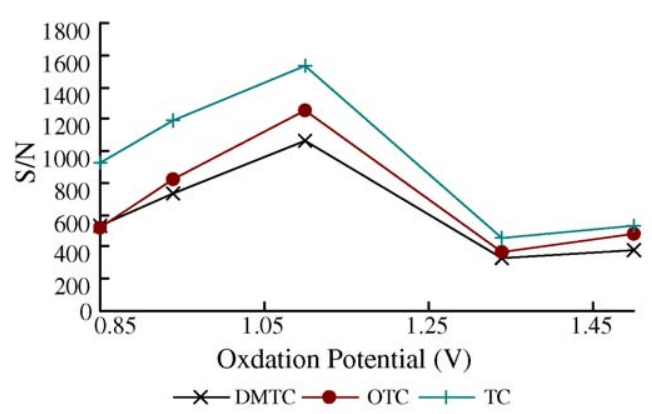

(D) The effect of oxdation potential on $\mathrm{S} / \mathrm{N}$ in waveform $\mathrm{B}$

Fig. 4. The effects of initial potential and oxidation potential on the ratio of signal/noise.

by Rockin et al. [28] and it is assumed that applying negative potential in waveform can produce hydrogen atoms on the surface of electrode from the reduction of water; then the hydrogen atoms can displace the reaction products and impurities adsorbed on the surface of electrode. The other explanation is that the effect is probably related to the potential dependence of adsorption of organic compounds on solid electrodes with a maximum close to the potential of zero charge. It was reported that the use of the waveform containing a brief high negative cleaning potential resulted in significantly lower baseline for the detection of sulfur-containing compounds at an Au electrode [29]. We made exploration test on the effect of a brief, relatively high, negative cleaning potential on the detection of TCs. Through the experimental studies, it was found that when $-1.50 \mathrm{~V}$ was adopted as the negative cleaning potential, the chromatographic system exhibited better analytical performances.

The optimal waveforms of two forms are shown in Fig. 2. The two waveforms presented similar $\mathrm{S} / \mathrm{N}$ value; thus, a random choice of waveform B was used for the following work.

\subsection{Comparison studies with triple-potential waveform}

Under their optimal conditions, waveform A and waveform B were compared with a typical triple-potential waveform [1]. A mixture standard solution was injected 15 times successively at an injection volume of $20 \mu \mathrm{L}$, and the $\mathrm{S} / \mathrm{N}$ values and RSDs for DMTC, OTC and TC were obtained, and they are given in Table 1. Obviously, waveform A and waveform B present higher S/N and smaller RSDs, showing that our method based on MultiIPAD waveform had a superior sensitivity and reproducibility to the triple-potential waveform based method [1].

\subsection{Linearity and limits of detection}

Under its optimal conditions, the characteristics of analytical method using waveform B were examined and the results was shown in Table 2. The response of DMTC, OTC and TC varied linearly with six standard concentrations covering the range of $0.1-15 \mathrm{mg} / \mathrm{L}$ using waveform B. The detection limits based on three levels of the ratio of signal-to-noise were $0.07 \mathrm{ng} \mathrm{mL}^{-1}$

Table 1

Comparison of three different waveforms on the S/N ratios and RSDs for peak height of three TCs (15 injections)

\begin{tabular}{lllll}
\hline \multirow{4}{*}{ Compounds } & \multicolumn{2}{l}{ Potentials } & & \\
\cline { 3 - 5 } & & Waveform A & Waveform B & Triple-IPAD \\
\hline S/N & DMTC & 297 & 221 & 69 \\
& OTC & 264 & 211 & 15 \\
& TC & 413 & 296 & 22 \\
RSD & DMTC & $3.2 \%$ & $4.6 \%$ & $5.2 \%$ \\
& OTC & $4.4 \%$ & $3.8 \%$ & $5.1 \%$ \\
& TC & $2.7 \%$ & $4.3 \%$ & $9.8 \%$ \\
\hline
\end{tabular}

a Average $\mathrm{S} / \mathrm{N}$ ratio for 15 successive injections.

Table 2

Calibration and detection limits of DMTC, OTC and TC for the proposed waveform B

\begin{tabular}{llll}
\hline & Linear equation & Regression coefficient & $\begin{array}{l}\text { Detection limits } \\
(\mathrm{mg} / \mathrm{L})\end{array}$ \\
\hline DMTC & $Y=23.33 X$ & 0.9993 & 0.07 \\
OTC & $Y=21.10 X$ & 0.9997 & 0.08 \\
TC & $Y=30.89 X$ & 0.9997 & 0.05 \\
\hline
\end{tabular}


Table 3

Comparison of the detection limits of the present method with the other reported methods

\begin{tabular}{|c|c|c|c|c|}
\hline $\begin{array}{l}\text { Number of } \\
\text { method }\end{array}$ & Compound & Type of method & $\mathrm{LOD}(\mathrm{ng} / \mathrm{mL})$ & Reference \\
\hline 1 & $\mathrm{TC}$ & HPLC-UV & 5800 & [6] \\
\hline 2 & Four TCs & HPLC-UV & $500-2000$ & [7] \\
\hline 3 & Five TCs & SPE-HPLC-DAD & $<100$ & [8] \\
\hline 4 & Four TCs & SPE-HPLC-DAD & $117.2-131.3$ & [9] \\
\hline 5 & Two TCs & FIA-ECL & $3.8-4.0$ & {$[10]$} \\
\hline 6 & Three TCs & FIA-CL & $1-2 \times 10^{-6 a}$ & [11] \\
\hline 7 & Three TCs & HPLC-CL & $0.9-5.0$ & [12] \\
\hline 8 & CTC & HPLC-ESI-MS/MS & 50 & [13] \\
\hline 9 & Four TCs & HPLC-APCI-MS/MS & $1-4$ & [14] \\
\hline 10 & Three TCs & SPE-HPLC-MS/MS & $0.20-0.28$ & [15] \\
\hline 11 & $\mathrm{TC}$ & FIA-PAD (AuE) & $1.0 \times 10^{-6 a}$ & [1] \\
\hline 12 & Four TCs & HPLC-EC (GCE) & $10-200$ & [16] \\
\hline 13 & Four TCs & HPLC-PAD (BDDE) & $50-100$ & [17] \\
\hline 14 & Seven TCs & HPLC-EC (GCE) & $100-1000$ & [18] \\
\hline 15 & Five TCs & HPLC-CEA & $12.5-25$ & {$[20]$} \\
\hline 16 & OTC & FIA-EC (CFME) & 150 & [21] \\
\hline 17 & $\mathrm{TC}$ & $\mathrm{EC}(\mathrm{ABE})$ & $1.2 \times 10^{-8 \mathrm{a}}$ & {$[22]$} \\
\hline 18 & Four TCs & FIA-EC (NMGCE) & $30-1810$ & [26] \\
\hline 19 & Three TCs & HPLC-IPAD (AuE) & $50-80$ & This paper \\
\hline
\end{tabular}

${ }^{a} \mathrm{~mol} / \mathrm{L}$; SPE: solid-phase extraction; DAD: diode-array detection; FIA: flow injection analysis; ECL: electrochemiluminescence; CL: chemiluminescence; CTC: chlortetracycline; ESI-MS/MS: electrospray ionization-tandem mass spectrometry; APCI-MS/MS: atmospheric pressure chemical ionization tandem mass spectrometry; AuE: gold electrode; BDDE: boron-doped diamond thin film electrode; EC: electrochemical detection; NMGCE: nickel-modified glassy carbon electrode; CFME: carbon fiber microelectrode; ABE: acetylene black electrode in the presence of sodium dodecyl sulfate; GCE: glassy carbon electrode; CEA: coulometric electrode assay detection.

for DMTC, $0.08 \mathrm{ng} \mathrm{mL}^{-1}$ for OTC, $0.05 \mathrm{ng} \mathrm{L}^{-1}$ for TC, respectively. For comparison, the limits of detection of some other published methods for the determination of TCs in recent years are given in Table 3. From Table 3, we can find that the method developed by us is more sensitive than all the UV or DAD detection based methods. In comparison with other electrochemical detection based method, except for the methods based on the coulometric electrode assay detection [20] and on the usage of acetylene black electrode [22], our method is more sensitive than or roughly as sensitive as most of the other electrochemical detection based methods $[1,16-18,21,26]$. Compared with mass detection [13-15], electrochemiluminescence [10] and chemiluminescence $[11,12]$, the present method shows a relatively poorer sensitivity.

\subsection{Sample analysis and recovery tests}

In order to validate the accuracy and precision of the proposed method under the selected conditions, oxytetracycline tablets for animals had been analyzed by our HPLC-Multi-IPAD method.

Sample preparing process was performed according to the literature [18]. OTC tablets for animals were crushed into powder with a mortar and pestle. An accurately weighed portion of $0.3500 \mathrm{~g}$ was transferred to a $100 \mathrm{ml}$ volumetric flask and dissolved in mobile phase. A portion of this solution was filtered through a $0.22 \mu \mathrm{m}$ nylon filter and an aliquot of filtrate was
Table 4

Sample analysis result and recoveries of three compound standards spiked tablet solution using the waveform B

\begin{tabular}{lllll}
\hline Compound & $\begin{array}{l}\text { Found }^{\mathrm{a}} \\
(\mathrm{mg} / \mathrm{L})\end{array}$ & Spiked $(\mathrm{mg} / \mathrm{L})$ & Recovery $^{\mathrm{a}}(\%)$ & $\begin{array}{l}\text { RSD }(n=3) \\
(\%)\end{array}$ \\
\hline DMTC & 0 & 2.00 & 102.5 & 2.3 \\
OTC & 4.34 & 3.00 & 117.0 & 3.3 \\
TC & 0 & 3.00 & 111.0 & 3.5 \\
\hline
\end{tabular}

a Mean for three determinations.

diluted properly. Finally, $25 \mu \mathrm{L}$ of this solution was injected to the chromatographic system for analysis.

The recoveries of DMTC, OTC and TC were obtained by injecting a tablet solution (mentioned above) spiked with the standard samples. The baseline was clean without interfering. The results are shown in Table 4. From these results, we found that for all three tetracycline compounds, the spiked recoveries were satisfactory, showing no obvious matrix interferences in this kind of sample.

\section{Conclusion}

The experimental results show that Multi-IPAD waveform following HPLC separation can be successfully applied for the determination of tetracycline antibiotics. The optimized conditions were examined by varying the potential values in different waveform steps. In comparison to the most of other amperometric methods published in recent years [1,17], the proposed methods give lower detection limits and higher S/N. No obvious difference between the two waveforms proposed in this paper was observed. This method has been applied to determine some TCs in the real animal remedy tablet sample. Perhaps there is a possibility of the practical utility of the present method to analyze a low content of tetracycline antibiotics in other samples.

\section{Acknowledgements}

This work was jointly supported by the National Basic Research Program of China (2003CB415001) and National Natural Science Foundation of China (20475060, 20577058).

\section{References}

[1] S. Palaharn, T. Charoenraks, N. Wangfuengkanagul, K. Grudpan, O. Chailapakul, Anal. Chim. Acta 499 (2003) 191.

[2] United States Pharmacopoeia XXIII, United States Pharmacopoeial Convention, Rockville, MD, USA, 1995.

[3] N.D. Weng, S. Hua, E. Roets, J. Hoognatens, J. Pharm. Biomed. Anal. 33 (2003) 85

[4] J. Tjornelund, S.H. Hansen, J. Chromatogr. A 779 (1997) 235.

[5] C.L. Chen, X.L. Gu, J. AOAC Int. 78 (1995) 1369.

[6] J.M. Moreno-Cerezo, M. Cordoba-Diaz, D. Cordoba-Diaz, M. CordobaBorrego, J. Pharm. Biomed. Anal. 26 (2001) 417.

[7] L. Monser, F. Darghouth, J. Pharm. Biomed. Anal. 23 (2000) 353.

[8] N. Furusawa, Talanta 59 (2003) 155

[9] A.L. Cinquina, F. Longo, G. Anastasi, L. Giannetti, R. Cozzani, J. Chromatogr. A 987 (2003) 227.

[10] Y. Pang, H. Cui, H. Zheng, G. Wan, L. Liu, X. Yu, Luminescence 20 (2005) 8 . 
[11] A. Townshend, W. Ruengsitagoon, C. Thongpoon, S. Liawruangrath, Anal. Chim. Acta 541 (2005) 105.

[12] G. Wan, H. Cui, H. Zheng, J. Zhou, L. Liu, X. Yu, J. Chromatogr. B 824 (2005) 57.

[13] M. Cherlet, S. Croubels, P.D. Backer, J. Chromatogr. A 1102 (2006) 116-124.

[14] H. Nakazawa, S. Ino, K. Kato, T. Watanabe, Y. Ito, J. Chromatogr. B 732 (1999) 55.

[15] J. Zhu, D.D. Snow, D.A. Cassada, S.J. Monson, R.F. Spalding, J. Chromatogr. A 928 (2001) 177.

[16] W. Hou, E. Wang, Analyst 114 (1989) 699.

[17] T. Charoenraks, S. Chuanuwatanakul, K. Honda, Y. Yamaguchi, O. Chailapakul, Anal. Sci. 21 (2005) 241.

[18] A.G. Kazemifard, D.E. Moore, J. Pharm. Biomed. Anal. 16 (1997) 689.

[19] J. Zhu, D.D. Snow, D.A. Cassada, S.J. Monson, R.F. Spalding, J. Chromatogr. A 928 (2001) 177.
[20] F. Zhao, X. Zhang, Y. Gan, J. Chromatogr. A 1055 (2004) 109.

[21] L. Agui, G.M. Pedrero, P. Yanez-Sedeno, J.M. Pingarron, Electroanal 15 (2003) 601

[22] X. Dong, C. Hua, Y. Wei, W. Chen, S. Hu, Electroanalysis 23 (2003) 1949.

[23] T.R.I. Cataldi, D. Nardiello, J. Chromatogr. A 1066 (2005) 133.

[24] Y. Ding, H. Yu, S. Mou, J. Chromatogr. A 1039 (2004) 39.

[25] W.R. Lacourse, Pulsed Electrochemical Detection in High-performance Liquid Chromatography, Wiley, New York, 1997.

[26] W. Oungpipat, P. Southwell-Keely, P.W. Alexander, Analyst 120 (1995) 1559

[27] W.R. LaCourse, C.O. Dasenbrock, J. Pharm. Biomed. Anal. 19 (1999) 239.

[28] R.D. Rockin, A.P. Clarke, M. Weizhandler, Anal. Chem. 70 (1998) 1496.

[29] T.Z. Polta, D.C. Johnson, J. Electroanal. Chem. 209 (1986) 159. 